\title{
Recurrent Hyponatremia After Traumatic Brain Injury
}

\author{
CHIH-HUNG CHANG, MD; JUI-JUNG LIAO, MD; CHUNG-HUA CHUANG, MD; \\ CHIEN-TE LEE, MD, PHD
}

\begin{abstract}
Dysregulation of the neuroendocrine system is a frequent complication after traumatic brain injury (TBI). Symptoms of these hormonal abnormalities might be subtle and thus easily ignored. Hyponatremia usually indicates underlying disorders that disrupt fluid homeostasis. In most patients with TBI, hyponatremia is a feature of the syndrome of inappropriate antidiuretic hormone (SIADH) secretion due to pituitary dysfunction after head injury. Usually TBI-associated hyponatremia is transient and reversible. We report the case of a 48-year-old man with TBI-associated hyponatremia with delayed recovery and recurrent hyponatremia precipi-
\end{abstract}

$\mathbf{H}$ yponatremia is a common disorder encountered in various settings. ${ }^{1}$ In most cases, hyponatremia manifests as an underlying disease and degree of hyponatremia usually indicates severity of etiology, and can even correlate with patient outcome. ${ }^{2}$ Clinical features of hyponatremia are confined to most neurological manifestations, but vary with severity and rate of progression. Hyponatremia is one of the clues for diagnosing disease that might not be detected directly. Moreover, in certain circumstances, hyponatremia can even provide significant prognostic implications. ${ }^{1}$

Traumatic brain injury (TBI) may severely impair brain function. In addition to structural damage, neuroendocrine dysfunction is an important complication. ${ }^{3}$ The pituitary insult can manifest with any hormone dysregulation involving either the anterior or posterior pituitary gland.4,5 Most TBI-associated hyponatremia is mild and asymptomatic, and lasts only a short time. The syndrome of inappropriate

From the Division of Nephrology, Department of Internal Medicine (C-HC, C-HC, C-TL); and Division of Neurosurgery, Department of Surgery (J-JL), Chang Gung Memorial Hospital-Kaohsiung Medical Center, Chang Gung University College of Medicine, Taiwan, China.

Submitted May 10, 2007; accepted in revised form June 28, 2007.

Correspondence: Chien-Te Lee, $M D, P h D$, Division of Nephrology, Department of Internal Medicine, Chang Gung Memorial Hospital, No.123, Ta-Pei Road, Niao-Sung Shang, Kaohsiung Hsien 833, Taiwan, China (E-mail: ctlee33@adm.cgmh.org.tw). tated by subsequent surgery. In this report, we emphasize the importance of identifying patients with slow recovery of the injured brain, which could complicate with SIADH and acute hyponatremia. Differentiating TBI-associated SIADH from other important causes of hyponatremia such as cerebral salt wasting, and hypocortisonism are also reviewed. Prevention of its recurrence by avoiding further risk is mandatory in managing patients with TBI. KEY INDEXING TERMS: Hyponatremia; Head injury; Syndrome of inappropriate antidiuretic hormone secretion. [Am J Med Sci 2008;335(5):390-393.]

secretion of antidiuretic hormone (SIADH) commonly underlies acute hyponatremia in these patients. ${ }^{6}$ Because the neurological manifestations of hyponatremia and acute brain injury are quite similar, differentiation may be difficult. Furthermore, unresolved recurrent hyponatremia with obvious clinical manifestations has rarely been described. We report here a patient with recurrent symptomatic hyponatremia after head injury.

\section{Case Report}

A 48-year-old man was sent to our emergency department because of an accidental fall, and head injury 4 days before admission. He had originally been admitted to a local hospital where brain computed tomography revealed no intracranial hemorrhage or skull fracture. However, he developed progressive headaches, deteriorated consciousness, and vomiting that were refractory to medical treatment. Repeated brain computed tomography at our institution disclosed minimal bilateral frontal subdural hematoma. Biochemical examination found a rapid drop in serum sodium level to $122 \mathrm{mEq} / \mathrm{L} 2$ days after admission. On examination, the patient was euvolemic without signs of volume deficit. He had normal blood pressure throughout hospitalization, and no excessive urine output was noted. There was no decrease in body weight. Serum biochemistry panel drawn at admission showed glucose $117 \mathrm{mg} / \mathrm{dL}$, sodium $122 \mathrm{mEq} / \mathrm{L}$, osmolality 263 $\mathrm{mOsm} / \mathrm{kg} \mathrm{H}_{2} \mathrm{O}$, blood urea nitrogen $13 \mathrm{mg} / \mathrm{dL}$, and creatinine 0.7 $\mathrm{mg} / \mathrm{dL}$. No other electrolyte abnormalities were found. Urine biochemistry showed sodium $159 \mathrm{mEq} / \mathrm{L}$ and osmolality $710 \mathrm{mOsm} / \mathrm{kg}$ $\mathrm{H}_{2} \mathrm{O}$. Adrenal and thyroid function tests showed cortisol level 10.3 $\mu \mathrm{g} / \mathrm{dL}$ (normal, $3-13 \mu \mathrm{g} / \mathrm{dL}$, evening); thyroid stimulating hormone $1.75 \mu \mathrm{IU} / \mathrm{mL}$ (normal, $0.25-4.0 \mu \mathrm{IU} / \mathrm{mL}$ ); and free T4 $1.85 \mathrm{ng} / \mathrm{dL}$ (normal, $0.79-2.01 \mathrm{ng} / \mathrm{dL}$ ). He denied a history of hyponatremia and no medication-related hyponatremia was noted. A diagnosis of hyponatremia due to SIADH was thus made. 


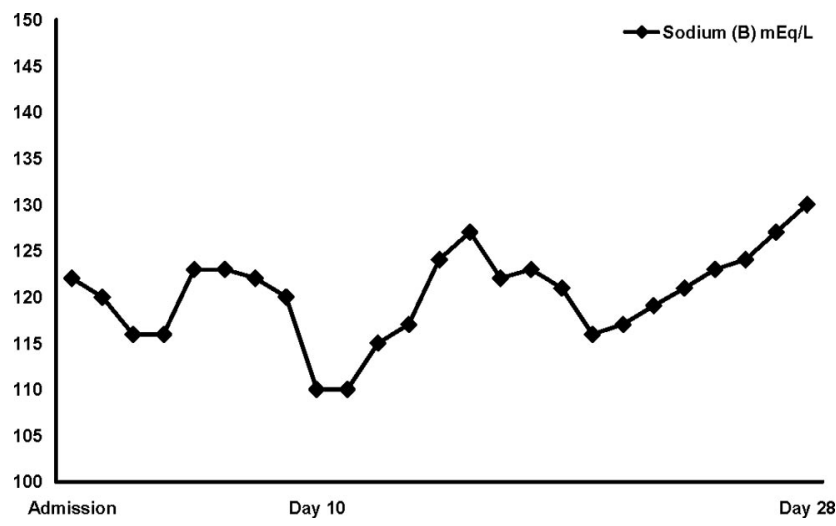

Figure 1. Changes in plasma sodium level during hospitalization for first hyponatremia episode.

The patient's clinical course was uneventful, with treatment including hypertonic saline $(3 \% \mathrm{NaCl})$ infusion and fluid restriction. His hyponatremia progressed after admission, with the lowest sodium level of $110 \mathrm{mEq} / \mathrm{L}$ on hospital day 10 . With gradual improvement, the sodium level returned to $130 \mathrm{mEq} / \mathrm{L}$ on day 28 (Figure 1). No surgery was performed for his small subdural hemorrhage and he was discharged thereafter. Unexpectedly, another 2 episodes of hyponatremia developed within months. The second episode occurred 2 months later, after surgery for a lumbar spine compression fracture, with the patient experienced severe headaches, vomiting, and epigastric burning. Routine blood tests showed a preoperation sodium level of 131 $\mathrm{mEq} / \mathrm{L}$. No symptoms were recorded at that time. There was no medicine use attributed to hyponatremia. His cortisol level was 24.9 $\mu \mathrm{g} / \mathrm{dL}$ (normal, 9-23 $\mu \mathrm{g} / \mathrm{dL}$, morning). There was no intravenous free water administration in pre- and postoperative periods. Physical examination and biochemical study supported the diagnosis of recurrent SIADH (Table 1). During hospitalization, the patient's hyponatremia progressed to a nadir at day 14 with sodium level $108 \mathrm{mEq} / \mathrm{L}$. Conservative treatment with water restriction was given and sodium level increased rather rapidly, accompanied by improvement in symptoms within 1 week. Sodium level increased to $130 \mathrm{mEq} / \mathrm{L}$ (Figure 2). The third episode occurred 20 days after the second discharge. The patient was readmitted for surgery for a displaced transpedicle screw. The preoperation sodium level was normal at $143 \mathrm{mEq} / \mathrm{L}$. However, the patient experienced recurrent headaches 1 week later and his sodium level went as low as $117 \mathrm{mEq} / \mathrm{L}$. Hormonal study revealed normal thyroid and adrenal functions (thyroid stimulating hormone, $2.34 \mu \mathrm{IU} / \mathrm{mL}$; cortisol, $23.9 \mu \mathrm{g} / \mathrm{dL}$ ). No intravenous free water was given while he was hospitalized. His hyponatremia was normalized with conservative treatment only. No later episodes of hyponatremia were identified, and the patient had no further hyponatremiarelated symptoms or signs.

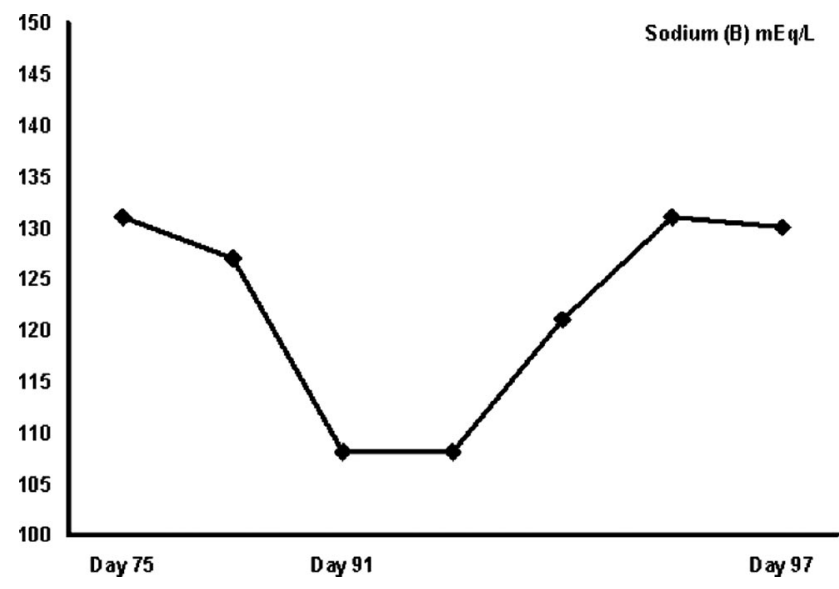

Figure 2. Changes in plasma sodium level during hospitalization for secondary hyponatremia episode.

\section{Discussion}

Hyponatremia is a common electrolyte disorder frequently observed in patients with a variety of central nervous system disorders and after many different neurosurgical procedures. ${ }^{7}$ Clinical symptoms are mainly neurological, in addition to nonspecific complaints. It is therefore necessary to be aware of this overlap and treat patients accordingly. Acute hyponatremia caused by SIADH in the setting of traumatic cerebral injury has a reported prevalence rate ranging from $2.3 \%$ to $36.6 \%$, depending on selection criteria, time of study, and follow-up period. ${ }^{8}$ Among all etiologies, SIADH accounts for more than $90 \%$ of cases of post-TBI hyponatremia. ${ }^{9}$ SIADH is thought to be caused by central nervous system disorders because of disorganized inputs from the osmoreceptor cells of the anterior hypothalamus and brainstem cardiovascular regulatory centers. ${ }^{10}$ Most TBI-associated hyponatremia occurs within 1 week after head injury and returns to normal within 6 months. Post-TBI hyponatremia is not related to severity of brain insult (ie, as measured by the Glasgow coma scale) or presence of brain edema. ${ }^{6}$

The development of recurrent severe hyponatremia with alternation in consciousness in our patient was unexpected. The first hyponatremia progressed

Table 1. Summary of Traumatic Brain Injury (TBI)-associated Hyponatremia

\begin{tabular}{|c|c|c|c|c|c|c|}
\hline & \multirow[b]{2}{*}{$\begin{array}{c}\text { Days After } \\
\text { TBI }\end{array}$} & \multirow[b]{2}{*}{ Duration $^{a}(\mathrm{~d})$} & \multicolumn{2}{|c|}{ Blood } & \multicolumn{2}{|c|}{ Urine } \\
\hline & & & $\begin{array}{l}\text { Sodium } \\
(\mathrm{mEq} / \mathrm{L})\end{array}$ & $\begin{array}{c}\text { Osmolality } \\
\left(\mathrm{mOsm} / \mathrm{kg} \mathrm{H} \mathrm{H}_{2} \mathrm{O}\right)\end{array}$ & $\begin{array}{l}\text { Sodium } \\
(\mathrm{mEq} / \mathrm{L})\end{array}$ & $\begin{array}{c}\text { Osmolality } \\
\left(\mathrm{mOsm} / \mathrm{kg} \mathrm{H}_{2} \mathrm{O}\right)\end{array}$ \\
\hline First hyponatremia & 4 & 28 & 122 & 263 & 159 & 710 \\
\hline Secondary hyponatremia & 75 & 22 & 121 & 249 & 84 & 532 \\
\hline Third hyponatremia & 125 & 14 & 128 & 259 & 151 & 472 \\
\hline
\end{tabular}

TBI, traumatic brain injury.

${ }^{a}$ The duration was calculated from the onset of hyponatremia until the highest sodium level was noted during that episode. 
slowly and sodium level increased gradually. However, the second and third episodes were noted immediately after operations without other remarkable etiology. Because we know experiencing an operation is among the most common causes of SIADH in hospitalized patients, it is reasonable to speculate that our patient had not recovered completely from the initial insult and was susceptible when confronted with further surgery, provoking the SIADH. The lowest sodium level $(108 \mathrm{mEq} / \mathrm{L})$ was detected during the secondary episode but a rather modest decline was found in the third episode. Although most insults are transient, one patient was reported to have TBI-associated SIADH at 1 year after injury. ${ }^{11}$ Our patient experienced recurrent hyponatremia precipitated by surgery (the apparent precipitating factor). This clinical feature illustrates a delayed recovery of pituitary function, and external stimuli, such as those produced by surgery, could induce SIADH with resulting hyponatremia.

In addition to SIADH, other causes of hyponatremia after head injury include cerebral salt wasting (CSW), glucocorticoid deficiency, medications, and aggressive use of intravenous fluids. ${ }^{9,12}$ By definition, SIADH is a syndrome with normal to mild increased volume with resultant hyponatremia. The excessive $\mathrm{ADH}$, acting on collecting ducts, enhances water reabsorption. Without volume deficit and in the absence of hypofunction of the thyroid and adrenal glands, hypo-osmolality with urine osmolality greater than maximal dilution and elevated urine sodium excretion are cardinal figures of SIADH. Our patient demonstrated typical laboratory abnormalities in 3 hyponatremia episodes and improved spontaneously solely with fluid restriction. The recently discovered arginine vasopressin receptor antagonist may be a potential therapeutic agent to treat TBIassociated SIADH, especially in patients with prolonged and symptomatic hyponatremia as observed in our patient. ${ }^{13,14}$ Another specific, rare, but important cause of post-TBI-associated hyponatremia is CSW. This syndrome is characterized by central nervous system lesions with association of renal sodium and chloride loss. Peters et $\mathrm{al}^{15}$ first described patients with neurological disorders complicated with increased renal sodium excretion and hyponatremia. Intact pituitary and adrenal function but renal defect in preserving sodium and chloride was found in later studies. ${ }^{16,17}$ Natriuresis and volume depletion with increased vasopressin secretion are typical presentations in CSW patients. There are several factors contributing to the development of CSW. Natriuretic substances from central nervous systems origin such as brain natriuretic peptide, atrial natriuretic peptide, and digitalis-like peptides can exert natriuretic effect directly on the kidney. ${ }^{18}$ Furthermore, the decrease in sympathetic nervous system outflow with resultant inhibition of renal tubular sodium reabsorption and aldosterone secretion aggravates urinary sodium loss. ${ }^{19}$ In the presence of volume deficit, vasopressin is elevated in response to hypovolemia. Differentiating between these 2 disorders is critical because treatments are quite different. The most reliable way to differentiate the 2 is to assess effective circulating volume in these patients, as laboratory features are similar. ${ }^{19}$

Impact of TBI on pituitary hormone secretion is distributed evenly between the anterior and posterior parts. The prevalence of anterior pituitary hormone deficiency has been estimated to be $28.4 \%$, with two-thirds of cases involving an isolated hormonal axis. ${ }^{20}$ The most commonly affected hormones are adrenocorticotropic hormone, gonadotropin, and growth hormone. Although we did not check adrenocorticotropic hormone, this patient had normal cortisol levels in 3 subsequent measurements and did not manifest with typical feature of acute adrenal failure as described. 9 These data did not support coexisting hypocortisonism in association with SIADH. On the other hand, about one-third of patients have complications with posterior pituitary dysfunction. ${ }^{6}$ Interestingly, TBI can elicit excessive excretion, as well as deficiency, of $\mathrm{ADH}$. In a large cohort study of post-TBI patients, incidence of diabetes insipidus was more common than SIADH. ${ }^{6}$ Both disorders result from posterior pituitary dysfunction associated with disturbance in sodium homeostasis. In severe diabetes insipidus, hypernatremia rather than hyponatremia is a common laboratory finding. Most pituitary hormones are reduced in TBIinduced pituitary dysfunction except for elevation of prolactine and $\mathrm{ADH}$. The reason is currently unknown. The clinical course of post-TBI pituitary dysfunction is not universal for all hormones involved. Some abnormalities can develop soon after brain insult, whereas others may present as late as 1 year later, and disease duration can vary. ${ }^{21}$

In conclusion, we reported a TBI patient with recurrent hyponatremia accompanied by neurological symptoms. The SIADH-related hyponatremia had a prolonged, gradual recovery and was provoked repeatedly by subsequent surgical procedures. This case report highlights the clinical significance of recurrent trauma-associated SIADH and the severity of hyponatremia. Continuous evaluation for hyponatremia is necessary for all patients post TBI.

\section{References}

1. Upadhyay A, Jabar BL, Madias NE. Incidence and prevalence of hyponatremia. Am J Med 2006;119(suppl 1):S30S35.

2. Lee CT, Guo HR, Chen JB. Hyponatremia in the emergency department. Am J Emerg Med 2000;18:264-8.

3. Kaufman HH, Timberlake G, Voelker J. Medical complications of head injury. Med Clin North Am 1993;77:43-60.

4. Powner DJ, Boccalandro C, Alp MS. Endocrine failure after traumatic brain injury in adults. Neurocrit Care 2006; 5:61-70. 
5. Lieberman SA, Oberoi AL, Gilkison CR. Prevalence of neuroendocrine dysfunction in patients recovering from traumatic brain injury. J Clin Endocrinol Metab 2001;86:2752-6.

6. Agha A, Thornton E, O'Kelly P. Posterior pituitary dysfunction after traumatic brain injury. J Clin Endocrinol Metab 2004;89:5987-92.

7. Cole CD, Gottfried ON, Liu JK. Hyponatremia in the neurosurgical patient: diagnosis and management. Neurosurg Focus 2004;16:E9.

8. Agha A, Sherlock M, Phillips J. The natural history of post-traumatic neurohypophysial dysfunction. Eur J Endocrinol 2005;152:371-7.

9. Agha A, Sherlock M, Thompson CJ. Post-traumatic hyponatraemia due to acute hypopituitarism. QJM 2005;98:463-4.

10. Wong LL, Verbalis JG. Systemic diseases associated with disorders of water homeostasis. Endocrinol Metab Clin North Am 2002;31:121-40.

11. Kumar PD, Nartsupha C, Koletsky RJ. Delayed syndrome of inappropriate antidiuretic hormone secretion 1 year after a head injury. Ann Intern Med 2001;135:932-3.

12. Palmer BF. Hyponatremia in patients with central nervous system disease: SIADH versus CSW. Trends Endocrinol Metab 2003;14:182-7.
13. Rabinstein AA. Vasopressin antagonism: potential impact on neurologic disease. Clin Neuropharmacol 2006;29:87-93.

14. Nathan BR. Cerebral correlates of hyponatremia. Neurocrit Care 2007;6:72-8

15. Peters JP, Welt LG, Sims EAH. A salt wasting syndrome associated with cerebral disease. Trans Assoc Am Physicians 1950;63:57-64

16. Welt LG, Seldin DW, Nelson WP. Role of the central nervous system in metabolism of electrolytes and water. Arch Intern Med 1952;90:355-78.

17. Cort JH. Cerebral salt wasting. Lancet 1954;1:752-4.

18. Singh S, Bohn D, Carlotti AP. Cerebral salt wasting: truths, fallacies, theories, and challenges. Crit Care Med 2002;30:2575-9.

19. Palmer BF. Hyponatraemia in a neurosurgical patient: syndrome of inappropriate antidiuretic hormone secretion versus cerebral salt wasting. Nephrol Dial Transplant 2000;15: $262-8$.

20. Agha A, Rogers B, Sherlock M. Anterior pituitary dysfunction in survivors of traumatic brain injury. J Clin Endocrinol Metab 2004;89:4929-36.

21. Agha A, Phillips J, O'Kelly P, et al. The natural history of post-traumatic hypopituitarism: implications for assessment and treatment. Am J Med 2005;118:1416. 